\title{
Resistance to scrapie in PrP ARR/ARQ heterozygous sheep is not caused by preferential allelic use
}

\section{P A Caplazi, K I O’Rourke, T V Baszler}

J Clin Pathol 2004;57:647-650. doi: 10.1136/icp.2003.012203

\begin{abstract}
Background: In sheep, susceptibility to scrapie, which is similar to human prion diseases such as Kuru and variant Creutzfeldt-Jakob disease (vCJD), is determined by prion protein (PrP) gene (Prnp) polymorphisms. Sheep with genotype $A R Q / A R Q$, denoting polymorphisms at codons 136 , 154, and 171, are susceptible, whereas those with genotypes $A R R / A R Q$ and $A R R / A R R$ are resistant, indicating dominance of $A R R$ over the $A R Q$ allele.

Aims: Based on familial CJD E200K, 129V, where preferential use of the 200E allele in EK heterozygous individuals confers resistance, heterozygous $A R R / A R Q$ sheep were used to test the hypothesis that resistance is caused by preferential use of the ARR allele.

Methods: After assessment of equivalent PrP expression across genotypes, allele use was analysed by sequencing reverse transcription polymerase chain reaction derived DNA clones containing the Prnp gene coding sequence.

Results: The ARR to $A R Q$ ratio was 1.1 in 133 clones, representing Prnp mRNA from three ARR/ARQ sheep, indicating equal use of both alleles.

Conclusions: Dominance of the resistant associated allele in sheep scrapie involves mechanisms other than the absence of $\operatorname{PrP}$ derived from the disease associated $A R Q$ allele.
\end{abstract}

S crapie is a prion disease in sheep that, similar to Kuru or variant Creutzfeldt-Jakob disease (vCJD), requires both prion exposure and a genetic susceptibility. Susceptibility is defined by amino acid polymorphisms in the single copy prion protein (PrP) gene, Prnp. ${ }^{1}$ Specifically, in sheep homozygous for $\mathrm{A}$ at position 136 and $\mathrm{R}$ at position 154, susceptibility is defined by $\mathrm{R}$ or $\mathrm{Q}$ at position $171 .^{2}$ The genotype ARQ/ARQ confers susceptibility, whereas (apart from a few reported exceptions) genotypes ARR/ARQ and ARR/ARR confer resistance. Similarly, a M/V polymorphism at Prnp codon 129 determines susceptibility to $\mathrm{vCJD}^{3}$ and Kuru, ${ }^{4}$ with partial resistance conferred by the $\mathrm{V}$ allele. Assuming that overall PrP expression is not affected by genotype, two main alternatives for the resistance of heterozygous individuals exist: $\operatorname{PrP}$ ARR is preferentially expressed or PrP ARR interferes with the conversion of PrP ARQ to $\operatorname{PrP}^{\mathrm{sc}}$.

There is a precedence for both protein-protein interference and preferential allelic expression in genetic resistance to acquired and hereditary transmissible spongiform encephalopathies (TSEs), respectively. In the case of protein-protein interference, dominant negative inhibition can be defined as the ability of PrP expressed from a resistance associated allele to render conversion of $\operatorname{PrP}$ to $\operatorname{PrP}^{\mathrm{sc}}$ inefficient. It has been shown that C-terminal residues in PrP determine the ability of $\operatorname{PrP}^{c}$ to convert to $\operatorname{PrP}^{s c}$ on interaction with exogenous $\operatorname{PrP}^{\mathrm{sc},}$, and it has been hypothesised that the affinity of $\operatorname{PrP}^{\mathrm{C}}$ to an endogenous cofactor ("protein $X^{\prime \prime}$ ) required for conversion accounts for this phenomenon. ${ }^{56} \mathrm{~A}$ putative binding region for protein $\mathrm{X}$ has been identified. ${ }^{7}$

"In the case of protein-protein interference, dominant negative inhibition can be defined as the ability of prion protein (PrP) expressed from a resistance associated allele to render conversion of PrP to PrPsc inefficient"

Supporting this concept, similar observations have been made in vivo using a transgenic mouse model. ${ }^{8}$ Notably, with regard to sheep scrapie, this last study used $\operatorname{Prnp}^{-/-}$and Prnp $^{+/+}$mice transgenic for mouse PrP with a Q167R mutation (corresponding to the $\mathrm{Q} / \mathrm{R}$ polymorphism at position 171 of sheep PrP). Because the 167R allele rendered Prnp $^{+/+}$mice partially resistant to intracerebral inoculation with Rocky Mountain Laboratory prions, it was concluded that the resistance associated $167 \mathrm{R}$ allele is dominant over the wild-type allele.

From that study, it follows that overexpression of a resistance associated allele, such as the ARR allele in sheep, could render heterozygous carriers resistant. Indeed, incomplete penetrance and delayed onset of disease in hereditary CJD E200K, 129V have been associated with preferential use of the wild-type $200 \mathrm{E}$ allele over the mutant $200 \mathrm{~K}$ allele for PrP expression in 200EK heterozygous carriers. In five of seven heterozygous individuals with preferential transcription, the $\mathrm{E}$ to $\mathrm{K}$ ratio was $>50$, indicating a near monoallelic origin of PrP in these individuals. ${ }^{9}$

\section{METHODS}

Because resistance mechanisms might be shared between hereditary and acquired prion diseases, we tested the hypothesis that the ARR allele is transcribed to the exclusion of ARQ in scrapie resistant ARR/ARQ heterozygous sheep. Sites of preclinical, rather than terminal, $\operatorname{PrP}^{\mathrm{SC}}$ accumulation were chosen for analysis because (a) primary lymphoid $\mathrm{PrP}^{\mathrm{sc}}$ accumulation is a feature of Kuru-type prion diseases and is essential for natural sheep scrapie ${ }^{3}$; ; (b) follicular dendritic reticulum cells (FDCs) at peripheral accumulation sites are early targets of accumulation in sheep scrapie $^{10}$; and (c) B cells, rather than brain, were used to demonstrate allelic preference in familial CJD E200K. ${ }^{9}$ Before assessment of PrP mRNA, sites of preclinical $\operatorname{PrP}^{\mathrm{sc}}$ accumulation were analysed for PrP expression by the indirect immunofluorescence assay (IFA) and western blotting (WB) in the ARR/ARQ (resistant) and ARQ/ARQ (susceptible) genotypes to ensure overall equivalent PrP expression within and between genotypes.

Abbreviations: CJD, Creutzfeldt-Jakob disease; Fab, antibody Fab fragment(s); FDC, follicular dendritic reticulum cell; IFA, indirect immunofluorescence assay; PCR, polymerase chain reaction; $\operatorname{PrP}$, prion protein; Prnp, prion protein gene; RT, reverse transcription; TSE, transmissible spongiform encephalopathy; VCJD, Creutzfeldt-Jakob disease, new variant; WB, western blotting 


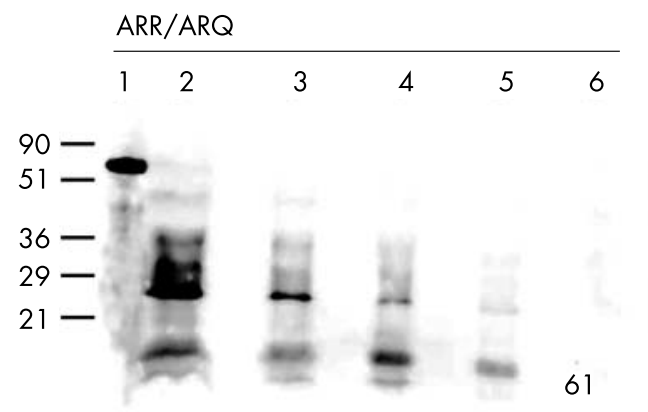

\begin{tabular}{llllll} 
ARR/ARQ & & & & \\
\hline 1 & 2 & 3 & 4 & 5 & 6
\end{tabular}

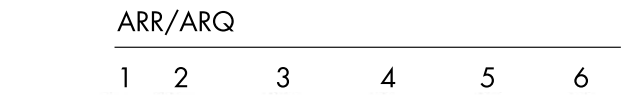

76

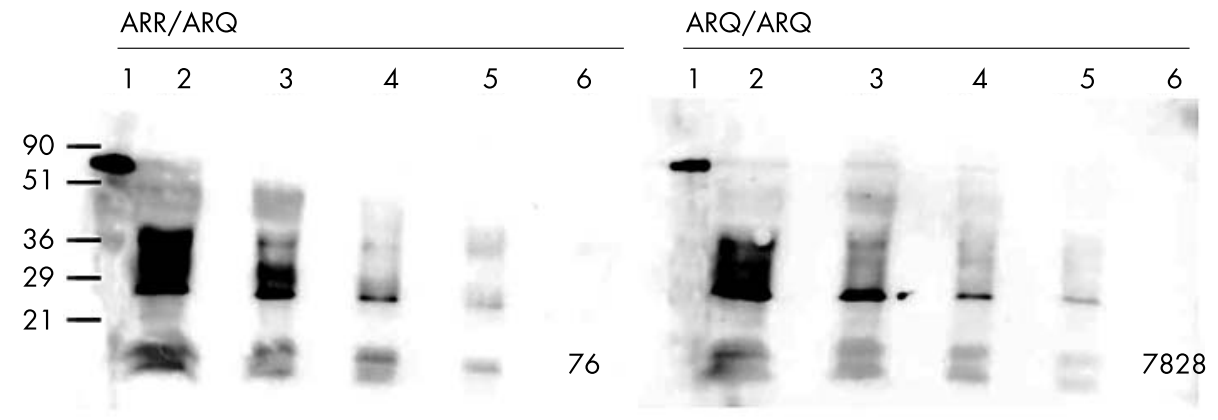

Figure 1 The detection limit of $\operatorname{PrP}^{c}$ by western blotting is identical in three resistant $A R R / A R Q$ sheep $(61,66,76)$ and one susceptible $A R Q / A R Q$ control (7828). Twofold dilution series of retropharyngeal lymph node lysates (lane 2, $5000 \mu \mathrm{g}$; lane 3, $2500 \mu \mathrm{g}$; lane 4, $1250 \mu \mathrm{g}$; lane 5, $625 \mu \mathrm{g}$; lane $6,313 \mu \mathrm{g}$ ) were probed with the PrP specific monoclonal antibody F99/ 97.6.1." Recombinant ovine PrP served as a positive control (lane 1). Molecular masses in $\mathrm{kDa}$ are indicated on the left. PrP, prion protein.
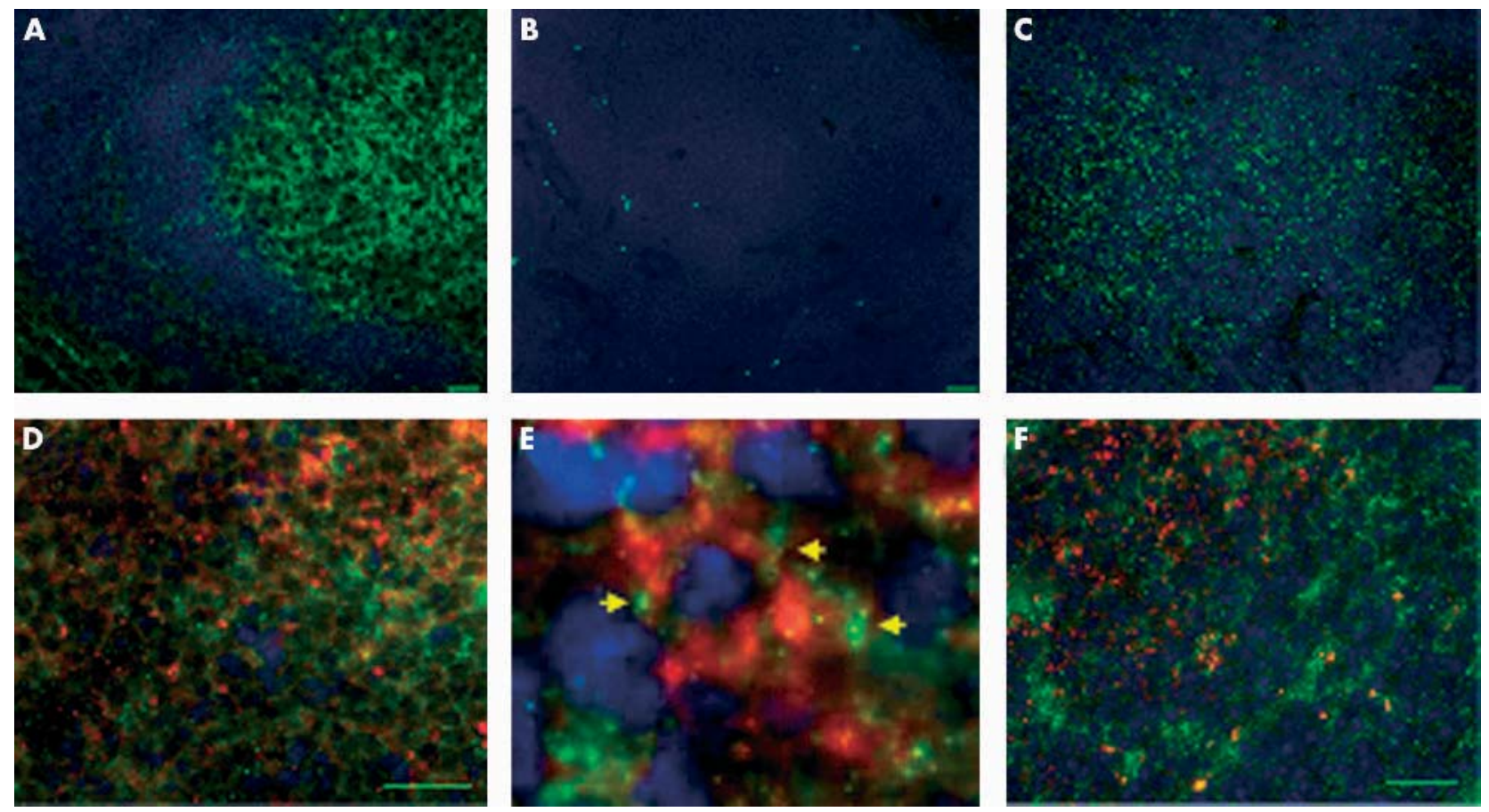

Figure 2 Equivalent prion protein (PrP) expression in gut associated lymphoid tissue from scrapie resistant and susceptible sheep by indirect immunofluorescence assay. (A) lleal Peyer's patch from sheep 61 with the resistant PrP genotype ARR/ARQ. PrP is ubiquitously expressed in round cells and stroma of a lymphoid follicle, and staining is particularly strong within the germinal centre. PrP (monoclonal antibody 7A12) is green (Alexa green); nuclei are blue (DAPI); bar, $20 \mu \mathrm{m}$. (B) Ileal Peyer's patch from sheep 61 with resistant PrP genotype ARR/ARQ. No fluorescent signal with irrelevant isotype matched control antibody (anti-Neospora caninum monoclonal antibody 5B6-25); bar, 20 um. (C) lleal Peyer's patch from sheep 7828 with susceptible PrP genotype ARQ/ARQ. Expression of $\operatorname{PrP}$ is similar to the heterozygous ARR/ARQ sheep shown in (A). PrP (monoclonal antibody 7A12) is green (Alexa green); nuclei are blue (DAPI); bar, $20 \mu \mathrm{m}$. (D) lleal Peyer's patch from sheep 66 (ARR/ARQ). Abundant PrP (green) is expressed in follicular dendtritic reticulin cells (FDCs) (red). Dual label immunofluorescence assay (IFA): PrP (7A12), Alexa green; FDC (CNA.42) Texas red; nuclei are blue (DAPI); bar, $20 \mu \mathrm{m}$. (E) Detail of panel (D), granular, mostly membrane associated PrP expression (arrows) in an FDC. (F) lleal Peyer's patch from sheep 7828 (ARQ/ARQ). Abundant PrP (green) is expressed by FDCs (red) in a pattern indistinguishable from ARR/ARQ sheep. Dual label IFA: PrP (7A12), Alexa green; FDC (CNA.42), Texas red; nuclei are blue (DAPI); bar, $20 \mu \mathrm{m}$. 

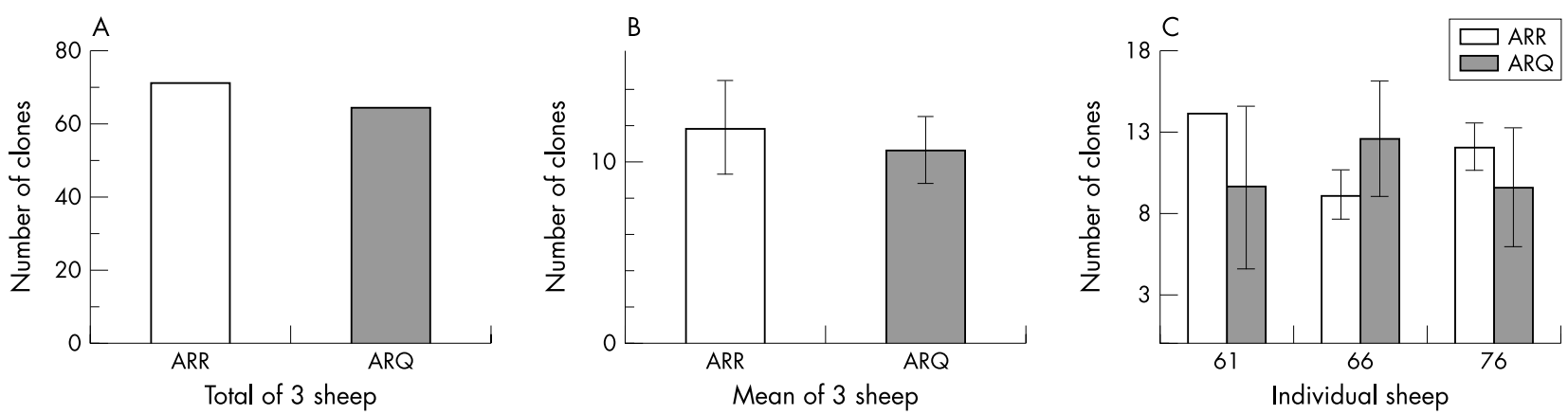

Figure 3 Use of the ARR and ARQ alleles in cDNA clones of the prion protein gene (Prnp) obtained from the lymph nodes of three ARR/ARQ heterozygous sheep (two experiments). (A) No significant difference in the use of the ARR and ARQ alleles in the total number of Prnp clones examined in all three sheep (sign test, $p=0.63$ ). (B) No significant difference in the use of the ARR and ARQ alleles in the mean of the Prnp clones examined in all three sheep. Error bars are one standard deviation of the mean. (C) No significant difference in the use of the ARR and ARQ alleles in the Prnp clones examined from the individual sheep. Error bars are one standard deviation of two experiments.

Three juvenile, healthy, not scrapie exposed ARR/ARQ Suffolk lambs (61, 66, and 76) and one matched healthy ARQ/ARQ control lamb (7828) were used. For WB, $100 \mathrm{mg}$ samples of retropharyngeal lymph node were lysed in $900 \mu \mathrm{l}$ lysis buffer (10mM Tris/HCl (pH 7.5) containing 0.5\% NP-40 and $0.5 \%$ deoxycholate), incubated with $200 \mu \mathrm{g} / \mathrm{ml}$ DNase, and centrifuged to remove cell debris. The PrP fraction was concentrated by centrifugation of lysate supernatants in a filter device with a $10 \mathrm{kDa}$ cut off. Serial twofold dilutions of concentrated lysate supernatants $(20 \mu \mathrm{l} / \mathrm{lane}$; wet tissue equivalents: $5000,2500,1250,625$, and $313 \mu \mathrm{g}$ ) were used in sodium dodecyl sulfate polyacrylamide gel electrophoresis on $14 \%$ gels. The positive control comprised $25 \mathrm{ng} / \mathrm{lane}$ of ovine recombinant PrP. The anti-PrP monoclonal antibody F99/97.6.1, ${ }^{11}$ followed by enhanced chemoluminescence (ECL; Amersham Biosciences, Piscataway, New Jersey, USA), were used for the detection of bands. For IFA, cryostatic sections were obtained from samples of ileum and mesenteric lymph node, fixed in P-fix (methanol/ phosphate buffered saline/glacial acetic acid, 50/49/1 vol/vol), and probed with monoclonal antibodies $7 \mathrm{~A} 12^{12}$ for PrP and CNA. $42^{13}$ for FDCs. PrP immunoreactivity was visualised using isotype specific biotinylated Fabs with subsequent tyramide amplification of an Alexa green signal (Molecular Probes, Eugene, Oregon, USA). FDCs were visualised using antibody Fab fragments (Fabs) conjugated with Texas red (Jackson ImmunoResearch Laboratories, West Grove, Pennsylvania, USA).

\section{RESULTS}

PrP expression was seen in the germinal centre of lymphoid follicles by single label IFA. Genotype specific differences in PrP expression were not evident by the detection limit in WB using serially diluted lymph node lysates (fig l). The $\operatorname{PrP}^{\mathrm{C}}$ detection limit in two separate experiments was $625 \mu \mathrm{g}$ wet tissue equivalents for all sheep tested, indicating relative equivalence of PrP expression. Furthermore, PrP signal intensity and distribution detected by IFA were similar for the ARR/ARQ (resistant) and ARQ/ARQ (susceptible) genotypes (fig 2A-C). Similarly, differences in the cellular specificity of PrP expression by dual IFA (fig 2D-F) were not found, indicating that genotype specific variations in PrP expression did not confound the interpretation of the allelic ratio of the PrP transcripts. In both genotypes, double label IFA confirmed the expression of PrP in FDCs, cells that are crucial in the pathogenesis of scrapie.

The allelic ratio of PrP transcripts was determined in three ARR/ARQ sheep by sequence analysis of reverse transcription polymerase chain reaction (RT-PCR) derived DNA clones.
Cloning and sequencing were chosen over probe based approaches to detect the single base polymorphism at position 171 because the procedures used (RNA isolation, reverse transcription, PCR, and cloning) are random with respect to the single base polymorphism. PrP transcripts isolated from mesenteric (first experiment) or retropharyngeal lymph nodes (second experiment) were analysed in two independent experiments. Total RNA was isolated from lymph nodes and reverse transcribed using oligo-dT primers after DNase digestion. cDNA was amplified by PCR (annealing at $60^{\circ} \mathrm{C}$ ) using the primers PrPl48F $5^{\prime}$-AACCGCTATC CACCTCAG and PrP637R 5'-CCACTCGCTCCATTATCT, which span a $491 \mathrm{bp}$ fragment within the PrP coding region containing codons 136, 154, and 171. Absence of genomic DNA in PCR was controlled for by mock RT reactions. PCR products were A-U cloned into pDrive (Qiagen, Valencia, California, USA) and sequenced through a commercial service (Amplicon Express, Pullman, Washington, USA). A single G/A polymorphism at base 365 of the insert corresponding to the second base in codon 171 was detected, as reported previously. ${ }^{1}$ The first experiment yielded 60 clones with an $\mathrm{R}$ to $\mathrm{Q}$ ratio of $37: 23$. The second experiment resulted in 73 clones with a ratio of $33: 40$. Overall, a slight predominance of ARR over ARQ was seen with a ratio of 1.1 (fig 3A), which was not significantly different from the expected ratio of 1.0 ( sign test, $\mathrm{p}=0.63$ ). Furthermore, the combined mean number of ARR and ARQ clones of all three sheep did not differ significantly (fig $3 \mathrm{~B}$ ), and there were no differences between the ARR and ARQ transcripts in the individual sheep (fig 3C). Accordingly, the hypothesis of differential allelic use, particularly preferential use of 171R, was rejected.

\section{Take home messages}

- Unlike resistance in hereditary familial CreutzfeldtJakob disease E200K, dominance of the resistant associated allele in sheep scrapie involves mechanisms other than the absence of prion protein derived from the disease associated $A R Q$ allele

- Mechanisms of genetic resistance vary among transmissible spongiform encephalopathies and may not be shared between hereditary familial and Kuru-type acquired prion diseases 


\section{DISCUSSION}

Therefore, unlike resistance in hereditary familial CJD E200K, resistance to scrapie in ARR/ARQ heterozygous sheep cannot be attributed to monoallelic mRNA transcription. Rather, our data show that both alleles are used with approximately equal frequency for Prnp transcription. We conclude that mechanisms of genetic resistance vary among TSEs and may not be shared between hereditary familial and Kuru-type acquired prion diseases. The relative genetic resistance of ARR/ARQ sheep must involve mechanisms other than simple absence of PrP ARQ. Such mechanisms may include interference of PrP ARR with $\operatorname{PrP}^{\mathrm{sc}}$ formation, directly by reducing the likelihood of productive initial interaction with the infectious prion, or indirectly by inhibiting interaction of nascent $\operatorname{PrP}^{\mathrm{sc}}$ with accessory molecules (protein $\mathrm{X}$ hypothesis). ${ }^{7}$ Finally, the relative lack of easily convertible substrate PrP ARQ may prolong the incubation period beyond the lifespan of the animal.

"The relative genetic resistance of $A R R / A R Q$ sheep must involve mechanisms other than simple absence of prion protein $\mathrm{ARQ}^{\prime \prime}$

\section{ACKNOWLEDGEMENTS}

We thank Drs M-S Sy and L Herrmann for the gift of the PrP monoclonal antibody 7A12, D Zhuang for technical assistance, and Dr P Cheevers for discussion of the manuscript. This work was supported by NRICGP/USDA grant 2002-35205-11648. P Caplazi was the recipient of a stipend from the Swiss National Science Foundation, which is gratefully acknowledged.

\section{Authors' affiliations \\ P A Caplazi, T V Baszler, Department of Veterinary Microbiology and Pathology, College of Veterinary Medicine, Washington State University, Pullman, WA 99164-7040, USA}

K I O'Rourke, United States Department of Agriculture, Agricultural Research Service, Animal Disease Research Unit, Pullman, WA 991647030, USA

Correspondence to: $\operatorname{Dr} \mathrm{T}$ Baszler, Department of Veterinary Microbiology and Pathology, Bustad Hall, Washington State University, Pullman, WA, 99164-7040, USA; baszlert@vetmed.wsu.edu

Accepted for publication 12 December 2003

\section{REFERENCES}

1 Goldmann W, Hunter N, Foster JD, et al. Two alleles of a neural protein gene linked to scrapie in sheep. Proc Natl Acad Sci U S A 1990;87:2476-80.

2 O'Rourke KI, Holyoak GR, Clark WW, et al. PrP genotypes and experimental scrapie in orally inoculated Suffolk sheep in the United States. J Gen Virol 1997:78:975-8.

3 Ironside JW. Pathology of variant Creutzfeldt-Jakob disease. Arch Virol Suppl 2000;16:143-51

4 Cervenakova L, Goldfarb LG, Garruto R, et al. Phenotype-genotype studies in kuru: implications for new variant Creutzfeldt-Jakob disease. Proc Natl Acad Sci U S A 1998:95: 13239-41.

5 Telling GC, Scott M, Mastrianni J, et al. Prion propagation in mice expressing human and chimeric PrP transgenes implicates the interaction of cellular PrP with another protein. Cell 1995;83:79-90.

6 Zulianello L, Kaneko K, Scott M, et al. Dominant-negative inhibition of prion formation diminished by deletion mutagenesis of the prion protein. I Virol 2000;74:4351-60.

7 Kaneko K, Zulianello L, Scott $M$, et al. Evidence for protein X binding to a discontinuous epitope on the cellular prion protein during scrapie prion propagation. Proc Natl Acad Sci U S A 1997:94:10069-74.

8 Perrier V, Kaneko K, Safar J, et al. Dominant-negative inhibition of prion replication in transgenic mice. Proc Natl Acad Sci U S A 2002;99:13079-84 9 Rosenmann H, Halimi M, Kahana I, et al. Differential allelic expression of PrP mRNA in carriers of the E200K mutation. Neurology 1997:49:851-6.

10 Heggebo R, Press CM, Gunnes $G$, et al. Distribution and accumulation of PrP in gut-associated and peripheral lymphoid tissue of scrapie-affected Suffolk sheep. J Gen Virol 2002;83:479-89.

11 O'Rourke KI, Baszler TV, Besser TE, et al. Preclinical diagnosis of scrapie by immunohistochemistry of third eyelid lymphoid tissue. J Clin Microbiol 2000:38:3254-9.

12 Li R, Liu T, Wong BS, et al. Identification of an epitope in the $C$ terminus of normal prion protein whose expression is modulated by binding events in the $\mathrm{N}$ terminus. J Mol Biol 2000;301:567-73.

13 Raymond I, Al Saati T, Tkaczuk J, et al. CNA.42, a new monoclonal antibody directed against a fixative-resistant antigen of follicular dendritic reticulum cells. Am J Pathol 1997;151:1577-85. 